\title{
Synthesis of carbon nanotube using ferrocene as carbon source and catalyst in a vertical structured catalyst reactor
}

\author{
Praswasti PDK Wulan ${ }^{1, *}$ and Ghassan Tsabit Rivai ${ }^{2}$ \\ ${ }^{1}$ Department of Chemical Engineering, Faculty of Engineering, Universitas Indonesia, Kampus UI-Depok, Jawa Barat 16424, \\ Indonesia \\ ${ }^{2}$ Sustainable Energy Research Group, Department of Chemical Engineering, Faculty of Engineering, Universitas Indonesia, \\ Kampus UI-Depok, Jawa Barat 16424, Indonesia
}

\begin{abstract}
Development of nano-carbon technology in the world has recently occurred due to its excellent electric, thermal, and mechanical properties and it diverse of applications such as electronics, biology, and material. Fixed bed reactor run into blocked due to carbon deposition on the catalyst that cause pressure drop enhancement. Whereas, application of fluidized bed reactor as an alternative of prior reactor have some trouble for complicated of feed flow control that can cause change of catalyst particle size during reaction since agglomeration and adhesion of nanoparticles transpire. Synthesis of carbon nanotube material used a vertical structured catalyst gauze reactor with double furnace system to maintain the catalyst and carbon source in the form of gas phase. This will lead growth of CNT on the surface of the substrate proved by SEM and XRD characterization. Furnace 1 used to ferrocene vaporizer at $400^{\circ} \mathrm{C}$ and furnace 2 provide substrate placement for CNT growth at $850^{\circ} \mathrm{C}$. CNTs characterization confirmed yield and CNT diameter $29.33 \%$ and $11.38 \mathrm{~nm}$ respectively. Characterization of SEM show that CNT grows on stainless steel type 316 substrate preferable with oxidative heat treatment. Nevertheless, CNTs product still contain many of impurities such as $\mathrm{Fe}_{3} \mathrm{O}_{4}, \mathrm{Fe}_{2} \mathrm{O}_{3}, \mathrm{Fe}_{3} \mathrm{C}$, hexagonal graphite, and amorphous carbon.
\end{abstract}

\section{Introduction}

Carbon Nanotube (CNT) is one of material in nanomaterial technology, its existence became popular due to its unique properties on optical absorption, electrical conductivity, and high thermal. Properties of CNT influenced by its arrangement. Unique properties of CNT obtained when it have collateral structure of nanocarbon. Hitherto, production and development of CNTs in the world is still faintly, this is due to design parameters that generally affect process of CNT growth such as type of substrate and carbon source. Furthermore, synthesis reactor can be one of parameters to produces better properties of CNT and morphology.

Fixed bed reactor used to produce CNT but it acquire discontinuation caused carbon decomposition on the catalyst lead to pressure drop enhancement. As an alternative, fluidized bed reactor adequate to scrape the carbon particle to prevent carbon deposition but this reactor have some trouble for complicated feed flow control that can caused change of catalyst particle size during reaction since agglomeration and adhesion of nanoparticles transpire. Moreover, change of particle catalyst size in consequence of hydrocarbon dissolution on carbon nanotube synthesize mechanism [1]. In the previous study, horizontal gauze reactor with thermal chemical vapour deposition (T-CVD) developed to production of CNT [2]. This CVD system is one of popular and better method to produce CNT than laser ablation and electric arc discharge in the scale of production. This horizontal catalyst reactor has not been able to produce Aligned CNT because of generated carbon loss more than $65 \%$, it is due to the error of feed gas reckoning moreover this reactor cannot maintain catalyst phase to attain the substrate for the growth of CNT [1]. Floating catalyst chemical vapour deposition (FC-CVD) with double furnace system used to produce CNT based on ferrocene by optimizing the heat transfer phenomena towards catalyst sublimation and carbon source.

Ferrocene has dual function, it could act as catalyst and carbon source because it has $\mathrm{Fe}\left(\mathrm{C}_{5} \mathrm{H}_{5}\right)_{2}$ chemical structured and effective to produce CNT even ACNT in optimum sublimation temperature and period. Ferrocene was vaporised to hydrocarbon (i.e. $\mathrm{CH}_{4}$ and $\mathrm{C}_{5} \mathrm{H}_{6}$ ) and catalyst $(\mathrm{Fe})$ at temperature more than $400^{\circ} \mathrm{C}[3]$.

In this study, vertical catalyst gauze reactor with double furnace system aims to produce CNT with carbon source and catalyst will attain the substrate in vertical axis. The double furnace system consist of furnace 1 as a placement and vaporizer of carbon source and furnace 2 as a placement of substrate. Ferrocene as a carbon source and catalyst was placed in the bottom of reactor (furnace 1) while the substrate was placed at the reactor 2 (furnace 2). Inert gas for this synthesis is argon gas to assist the CNT production. Furthermore, this reactor equipped with cyclone as CNT container. The modification of this synthesis reactor can solve of

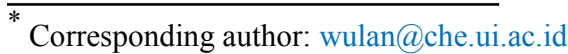


complicated parameters CNT production based on heat capacity with 4 grams ferrocene activation energy in each part of vertical reactor and stipulate ferrocene to decrease some problems of various catalyst and carbon source.

\section{Materials and method}

The experimental set-up used in this research is the vertical structured gauze catalyst reactor with double furnace system. The reactor were placed into the furnace with total height of reactor is $737 \mathrm{~cm}$ with $3 \mathrm{~cm}$ diameter. The reactor material used in this research is quartz tube with boiling point more than $1710^{\circ} \mathrm{C}$. Figure 1 shows the reactor modification and reactor components of experimental setup for CNT synthesis.
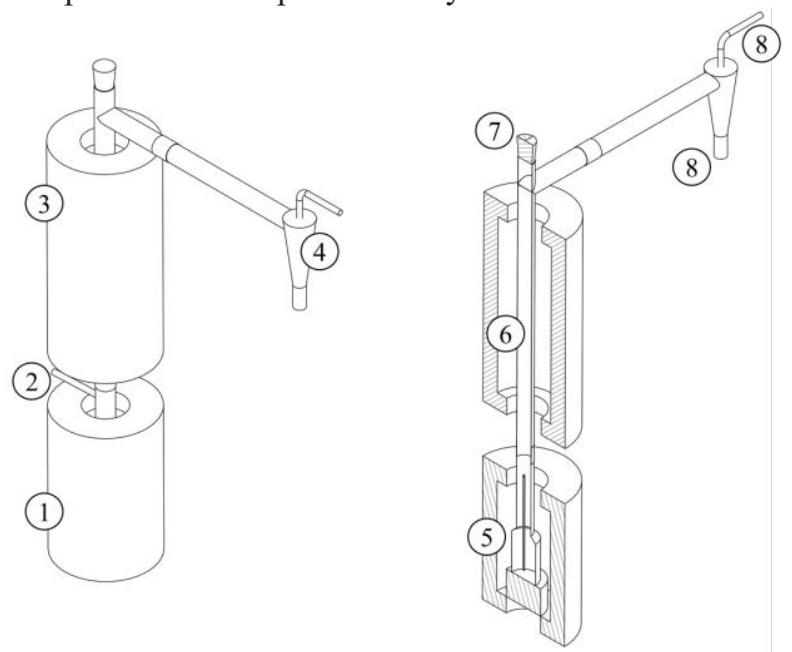

Fig. 1. The reactor modification of experimental setup for CNT synthesis

Table 1. Description of reactor modification

\begin{tabular}{|l|c|c|c|}
\hline 1 & Furnace 1 & 5 & Vaporizer (Reactor 1) \\
\hline 2 & Gas Input & 6 & Substrate Spot (Reactor 2) \\
\hline 3 & Furnace 2 & 7 & Thermocouple Input \\
\hline 4 & Cyclone & 8 & Gas Output \\
\hline
\end{tabular}

This study started by preliminary test such as flowmeter calibration, furnace calibration, reactor leakage test, and effective zone of substrate placement followed by synthesis of CNT. Stainless steel type 316 used as a substrate for this synthesis because it proven can reduce the carbon loss than the other type of stainless steel (i.e. foil and plate) [4]. To activate the catalyst, oxidative heat treatment needed to scrape chrome layer on stainless steel. Argon (gas) used as inert gas of this CNT production to assist carbon source and catalyst to reach substrate in reactor 2 with $150 \mathrm{~cm}^{3} / \mathrm{min}$ gas feed flow. Thermocouple used to maintain the temperature inside the reactor.

Several variations of placement and size of substrate performed to receive highest yield and lower carbon loss to produce CNT. In addition, oxidative heat treatment for substrate added to get well CNT morphology. 4 grams of ferrocene as carbon source and catalyst was base for each variations.
The FC-CVD method used in this research with temperature of $\mathrm{CNT}$ synthesis is $850^{\circ} \mathrm{C}$ and vaporizer temperature of ferrocene was $300^{\circ} \mathrm{C}$ and $400^{\circ} \mathrm{C}$ with atmospheric pressure and takes 20 minutes of synthesis period.

The CNT products were characterized using scanning electron microscopy (SEM; OJOL JSM 6510L), X-ray diffraction (XRD; Shimadzu 7000 Maxima-X), and energy dispersive $\mathrm{X}$-ray spectroscopy (EDX; ASTM E1508-2012), whilst the gas output were characterized by gas chromatography type thermal conductivity detector (GC-TCD) to find out the optimum time and temperature for CNT synthesis.

\section{Results and discussion}

\subsection{Design and modification of reactor}

Size of the reactor adjusted to the total energy required at the bottom and top of the reactor. Table 2 shows the total energy of heat on the reactor.

Table 2. Total Heat Energy

\begin{tabular}{|c|c|}
\hline Part of Reactor & Total Energy $(\mathrm{kJ} / \mathrm{s})$ \\
\hline Reactor 1 & 2.762 \\
\hline Reactor 2 & 3.133 \\
\hline
\end{tabular}

The result on Table 2 shows energy of heat capacity for each part reactor has exceeded heat requirement for production of CNT with ferrocene (4 grams) that is $1,892 \mathrm{~kJ} / \mathrm{s}$ based on its activation energy. Radiation, conduction, and convection heat transfer determined by heat transfer formula at reactor 1 and 2 respectively. Vertical reactor used in this study, similar with fluidized bed reactor as CNTs production, but has not have a bed. In fluidized bed reactor, agglomerate of nanoparticle and pressure drop changes was obtain [5]. In this study, ramp-up and ramp-down streamlines profile take place inside vertical CVD reactor. Recirculating zone develops when carbon source and catalyst reach the horizontal substrate at reactor 2 and due to concentration of the gas as it enters cooler zone at the gap of these two furnace. This induce to transport of concentration from the bottom of reactor to the substrate placement in reactor $2[6]$.

\subsection{Decomposition of ferrocene}

The objective of this step is to know compound of ferrocene decomposition and observe vaporizing of ferrocene (placed in reactor 1) to reach on substrate that placed in reactor 2 . Temperature was variated in furnace 1 in the amount of $300^{\circ} \mathrm{C}$ and $400^{\circ} \mathrm{C}$. This temperature ware selected because above $300^{\circ} \mathrm{C}$, organometallic compound (i.e. ferrocene, cobaltocene) will completely decomposed to its derivatives [3]. Gas chromatography type thermal conductivity detector (GC-TCD) used to find out decomposition of ferrocene. The GC-TCD output indicate ferrocene will decomposed to iron (Fe), methane $\left(\mathrm{CH}_{4}\right)$, hydrogen $\left(\mathrm{H}_{2}\right)$, and cyclopentadiene 
$\left(\mathrm{C}_{5} \mathrm{H}_{6}\right)$ corresponding decomposition reaction in Barreiro's [7].

Table 3. Gas component by GC-TCD

\begin{tabular}{|c|c|c|}
\hline Component & $300^{\circ} \mathrm{C}$ & $400^{\circ} \mathrm{C}$ \\
\hline $\mathrm{CH}_{4}(\%$-wt $)$ & 1.12 & 2.39 \\
\hline $\mathrm{H}_{2}(\%$-wt $)$ & 3.30 & 10.26 \\
\hline
\end{tabular}

Based on Table 3, more than $\sim 7 \%$ of hydrogen obtained at $400^{\circ} \mathrm{C}$ from decomposition of ferrocene temperature. Nevertheless, unknown compound in chromatogram ware detected, that allegedly is cyclopentadiene and other impurities compound (i.e. air). At $300^{\circ} \mathrm{C}$, slight of hydrogen and methane compound was discover. This suitable from prior study that mentioned ferrocene will completely decomposed to methane and hydrogen at temperature above $500^{\circ} \mathrm{C}$ [3]. Hence, this study used double furnace system to tide over decomposition problem. Furnace 2 will set at $850^{\circ} \mathrm{C}$ and take 20 minutes of synthesis 4 grams ferrocene. This period determined with GC-TCD, when the ferrocene decomposition achieve 20 minutes, unknown compound increased and detected by chromatogram shown on Table 4.

Table 4. Gas component by GC-TCD at $0-30 \mathrm{~min}$ period

\begin{tabular}{|c|c|c|c|c|c|c|c|}
\hline Var. & $\begin{array}{c}0 \\
\text { min }\end{array}$ & $\begin{array}{c}5 \\
\text { min }\end{array}$ & $\begin{array}{c}10 \\
\text { min }\end{array}$ & $\begin{array}{c}15 \\
\text { min }\end{array}$ & $\begin{array}{c}20 \\
\text { min }\end{array}$ & $\begin{array}{c}25 \\
\text { min }\end{array}$ & $\begin{array}{c}30 \\
\text { min }\end{array}$ \\
\hline $\mathrm{CH}_{4}$ & 7.6 & 13.6 & 8.7 & 19.9 & 14.3 & 8.3 & 7.2 \\
\hline $\mathrm{H}_{2}$ & 1.1 & 3.5 & 4.1 & 6.8 & 5.7 & 2.7 & 3.8 \\
\hline
\end{tabular}

Table 4 show, when the period of CNTs synthesis transcend 20 minute, methane and hydrogen compound decrease by time, so 20 minutes selected to be period of synthesis with this reactor. Methane and light hydrocarbon (i.e. methane, ethane) desired in CNT production, because it will be deposit on catalytic substrate not on reactor walls. Aromatic hydrocarbon would encourage the carbon loss and yield decreases. Furthermore, increasingly of carbon compound and few of iron compound will make thinner and longer CNT [8].

\subsection{Effect of oxidative heat treatment}

Oxidative heat treatment for stainless steel type 316 done for 20 minutes. It is based from roughness to period curve in prior study, when the period of pretreatment over than 20 minutes it is resulted $\pm 35 \mathrm{~nm}$ (optimum roughness) of stainless steel type 316 [2]. Substrate with rough surface will make carbon lodge on substrate and assist the growth of CNT. Thereto, chrome layer $\left(\mathrm{Cr}_{2} \mathrm{O}_{3}\right)$ will removed by this treatment to activate the metal alloy $(\mathrm{Fe})$ as catalyst on substrate. Chrome layer which still exists on stainless steel substrate, will preserve the iron metal by maintain from occurrence of corrosion that should be the catalyst on CNT growth [9]. This preparation will also eliminate molybdenum (Mo) compound that obstruct reactivity of substrate in CNT growth. Table 5 shown the component of substrate with and without oxidative heat treatment by EDX characterization.

Table 5. Result of EDX compound

\begin{tabular}{|c|c|c|}
\hline Component & With treatment & Without treatment \\
\hline $\mathrm{C}(\%-w t)$ & 73.7 & 59.96 \\
\hline $\mathrm{O}(\%-w t)$ & 8.17 & 4.03 \\
\hline $\mathrm{Fe}(\%-w t)$ & 16.48 & 34.57 \\
\hline
\end{tabular}

Substrate with oxidative heat treatment will changes equilibrium between $\mathrm{Fe}$ and $\mathrm{C}$ on stainless steel [2]. Content of oxygen compound increased because presence of air. Oxygen will broke surface of substrate to form more reactive surface for CNT growth. Radical-O will produced with this treatment to reduce impurities on CNT [10]. Carbon mass percentage increasing with this pretreatment and cause mount of CNT yield. Fe component increased as well since obtained from activated stainless steel type 316 and carbon source for activated substrate. Yield enhancement of CNT with oxidative heat treatment approach $\sim 32 \%$. This result, show that oxidative heat treatment will promote growth of CNT in a stainless steel substrate.
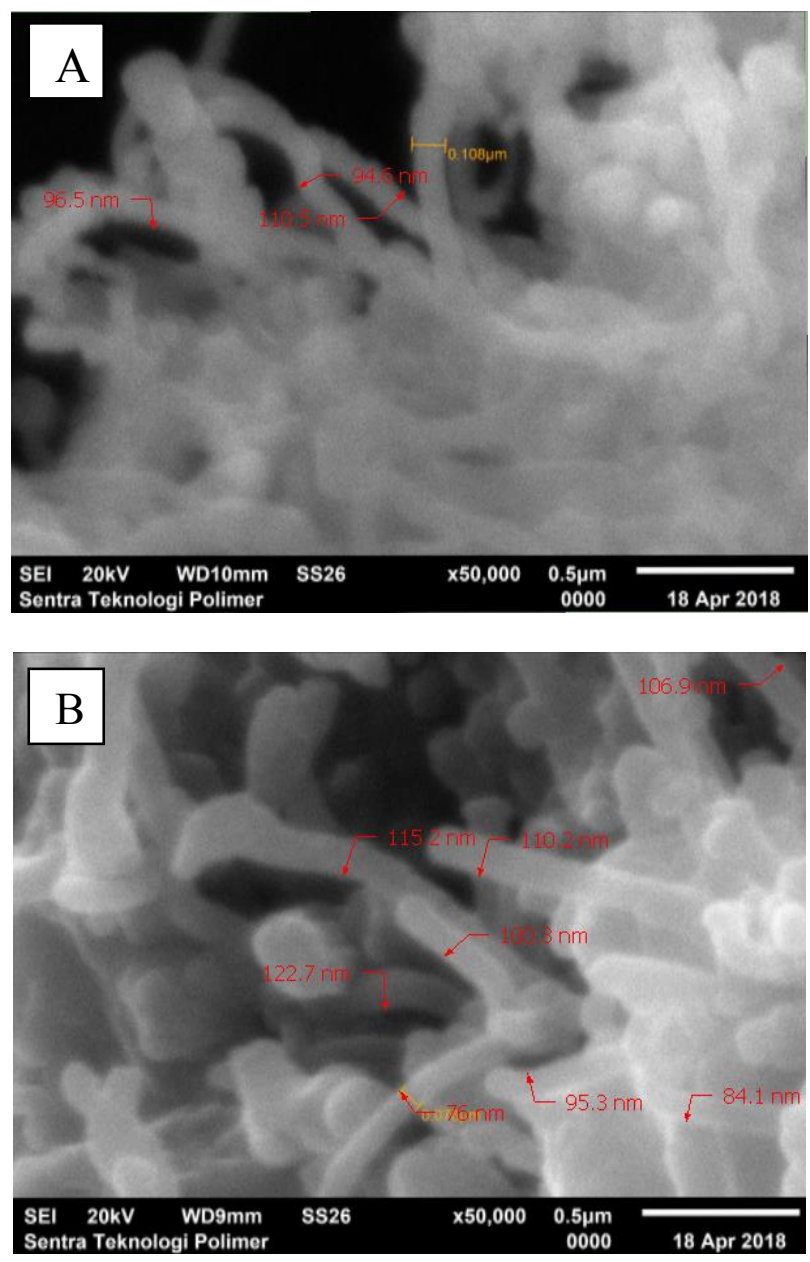

Fig. 2. (A) CNT with non-oxidative heat treatment; (B) CNT with oxidative heat treatment

Based on Figure 2, CNT more emerge with oxidative heat treatment. Nevertheless, the diameter of 
CNT lower with range of 76-122.7 $\mathrm{nm}$ in activated substrate than non-activated substrate with diameter 94.6-110.5 nm. Agglomerated occur when on CNTs because present of $\mathrm{Fe}_{3} \mathrm{C}$ core to create carbon onions like. Carbon onions are formed when temperature synthesis over $600^{\circ} \mathrm{C}$. Carbon onion structure consist of concentric carbon layers with surrounded of metal particles [11].

\subsection{Synthesis of carbon nanotube with vertical structured gauze reactor}

Stainless steel type 316 variated in horizontal form to find CNT with higher yield and lower carbon loss. Substrate placed in effective zone in reactor 2 . Horizontal substrate with high contact area in amount of $37.68 \mathrm{~cm}^{2}$ resulting high CNTs yield on stainless steel type 316 substrate.

In addition, pretreatment process and sublimation temperature (furnace 1) was variated on horizontal substrate to find out the impact of oxidative heat treatment towards yield of CNT.

Table 6. The effect of substrate variation to CNT yield

\begin{tabular}{|c|c|c|}
\hline $\begin{array}{c}\text { Horizontal } \\
\text { substrate }\end{array}$ & $\begin{array}{c}\text { Mass of CNT } \\
\text { (grams) }\end{array}$ & Yield (\%) \\
\hline $\begin{array}{c}300^{\circ} \mathrm{C} \text { with } \\
\text { Treatment }\end{array}$ & 0.97 & 24.25 \\
\hline $\begin{array}{c}300^{\circ} \mathrm{C} \text { without } \\
\text { treatment }\end{array}$ & 0.68 & 17.02 \\
\hline $\begin{array}{c}400^{\circ} \mathrm{C} \text { with } \\
\text { treatment }\end{array}$ & 2.15 & 53.69 \\
\hline $\begin{array}{c}400^{\circ} \mathrm{C} \text { without } \\
\text { treatment }\end{array}$ & 0.84 & 21.00 \\
\hline
\end{tabular}

Based on Table 6, it can be seen that the variation of substrate treatment cause different of yield. Substrate with pretreatment will result higher CNT yield with $\sim 50 \%$. Horizontal substrate resulting higher yield obtained from high sublimation of ferrocene temperature. Higher yield was obtain because of minimum carbon loss in horizontal substrate variation caused of surface contact area. While, higher sublimation temperature will control carbon source from ferrocene to produce hydrocarbon for CNT core.

$\mathrm{Fe} / \mathrm{C}$ ratio is another $\mathrm{CNT}$ parameter that can affect yield and diameter of CNT [12]. For instance, lower $\mathrm{Fe} / \mathrm{C}$ ratio will produce spherical structure of nanomaterial namely carbon microspheres (CM). This present study have $\mathrm{Fe} / \mathrm{C}$ ratio of 0.469 , which is higher of ratio. Higher $\mathrm{Fe} / \mathrm{C}$ ratio will create higher amorphous carbon yield and more width of CNT diameter by agglomerated iron particles. Besides that, amorphous carbon obtained through incomplete pyrolysis proceed [13]. Increased of diameter of CNT due to larger particles forming in higher concentration of metal compound. Iron concentration also increase CNTs distribution of diameter broadened. Moreover, $\mathrm{Fe}$ particles will affected size and formation of CNT will be determined in temperature and $\mathrm{C}$ concentration [13]. The
SEM of CNT (Figure 3) showed impurities was produce in this study.
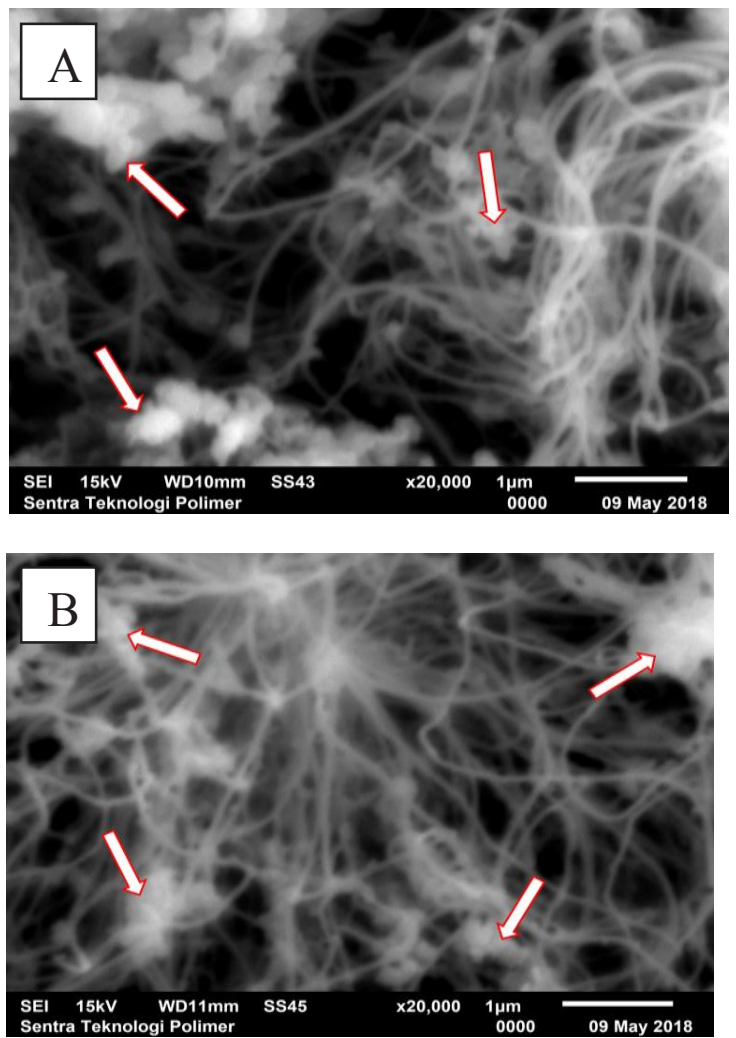

Fig 3. SEM of (a) CNT with oxidative heat treatment horizontal substrate; (b) CNT without oxidative heat treatment

The amorphous carbon with high peak obtained in each variation. Hence, the interaction of CNT make continuous bonding and CNT growth will agglomerated because of the van der waals force on each CNT. SEM characterization also told that growing model of CNTs following buckling and continuous growth. It take place because CNTs cannot expand more in catalyst so buckled and curved tube formed [14]. This result supported with XRD characterization in Figure 4.

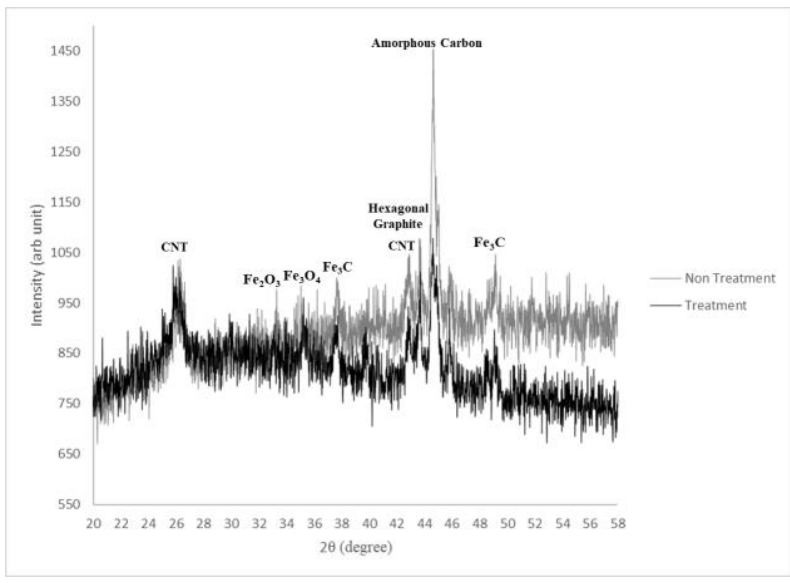

Fig 4. XRD of CNT with oxidative heat treatment and without on horizontal substrate variation

The results of XRD characterization in Figure 4 show that CNTs formed on each sample variation of 
substrate indicated by the presence of peak intensity at an angle of $2 \theta$ for CNTs of $26^{\circ}$ and $43^{\circ}$ [13]. The highest peak of amorphous carbon intensity obtained in samples with non-oxidative heat treatment. CNTs produced at peak $43^{\circ}$ is MWCNT with low quality nanomaterials [15]. Thereby, hexagonal graphite also formed at peak $43.7^{\circ}$. In addition, preparation of substrate will make less of amorphous carbon impurities because existing of oxygen compound that result radical-O. This compound will react with amorphous carbon to dispose and oxidize into $\mathrm{CO}_{\mathrm{x}}$ gas [10]. Amorphous carbon formed due to unmodified carbon to produce carbon impurities and aggregates in the process of CNT growth. Amorphous carbon also formed due to catalyst shooting caused by CNT growth termination process or saturated catalyst [9]. This XRD characterization related with SEM images. Based on Figure 4, CNTs formed with less amorphous carbon in oxidative atmosphere. In (A) picture, carbon nanotube with less amorphous carbon obtained and less tangled CNT growth formed.

Other than that, peaks of CNT and amorphous carbon there were several peaks indicate the presence of impurities on CNTs produced at each variation. The existence of compound iron (II,III) oxide because of reaction between iron from stainless steel substrate and ferrocene with oxygen atom with low selectivity. Nevertheless, iron (II,III) oxide obtained from reduction of $\mathrm{Fe}_{2} \mathrm{O}_{3}$ with $\mathrm{CO}$ by following Wijardono's statement [10].

$\mathrm{Fe}_{3} \mathrm{O}_{4}$ has lower peaks then other impurities in this synthesis. This may be due to the least amount of $\mathrm{CO}$ remaining to react to form $\mathrm{Fe}_{3} \mathrm{O}_{4}$ with Boudouard reaction. Whereas, impurities of $\mathrm{Fe}_{3} \mathrm{C}$ obtained from catalyst particle that get into "body" of CNT [2]. Moreover, $\mathrm{Fe}_{3} \mathrm{C}$ formed with interaction between $\mathrm{Fe}$ alloy and carbon gas and represent active phase of $\mathrm{Fe}$ for CNT growth [16].

From XRD characterization, size of crystal particle or diameter of particle can be analysed with Scherrer equation. Table 7 shows result of calculation mean size of CNT particle on substrate with and without oxidative heat treatment.

Table 7. Calculation of mean diameter CNT by XRD diffractogram

\begin{tabular}{|c|c|}
\hline Variation & $\begin{array}{c}\text { Mean size diameter } \\
\text { CNT }\end{array}$ \\
\hline $\begin{array}{c}\text { Substrate with Oxidative } \\
\text { Heat Treatment }\end{array}$ & $\sim 9.64 \mathrm{~nm}$ \\
\hline $\begin{array}{c}\text { Substrate without } \\
\text { Oxidative Heat Treatment }\end{array}$ & $\sim 12.63 \mathrm{~nm}$ \\
\hline
\end{tabular}

Substrate with oxidative heat treatment has lower diameter with accretion of carbon compound [8]. Based on Table 6, heat treatment process has affected diameter of CNT by activating of catalyst on substrate to encourage growth of CNT.

\section{Conclusion}

Ferrocene $\left(\mathrm{Fe}\left(\mathrm{C}_{5} \mathrm{H}_{5}\right)_{2}\right)$ can act as catalyst and carbon source to produce CNT with vertical structured gauze catalyst reactor. This reactor has three main part, that is vaporizer (reactor 1), substrate spot (reactor 2), and cyclone. Modification of this furnace and reactor design based on heat capacity of ferrocene sublimation energy. Preparation of oxidative heat treatment in substrate resulting more CNT growth on substrate stainless steel by increasing of carbon, oxygen, and iron compound. Withal this treatment, radical-O formed to reduce impurities specifically amorphous carbon on CNT production. Peak of impurities on XRD characterization will reduce on each substrate variation with this treatment. Diameter of CNT will reduce with oxidative heat treatment and temperature sublimation enhancement. Yield of CNT increased with less $\mathrm{Fe} / \mathrm{C}$ ratio and variation of horizontal substrate. Horizontal substrate will reduce carbon loss on CNT synthesis. In this study, $\mathrm{Fe} / \mathrm{C}$ ratio is 0.469 and producing high diameter and amorphous carbon besides no carbon microsphere formed.

\section{Acknowledgement}

The authors acknowledge the financial support received from Directorate of Research and Community Service Universitas Indonesia under PITTA Grant 2018 contract number: 2506/UN2.R3.1/HKP.05.00/2018. We are thankful, also, to Laboratory of Chemical and Resource Product Engineering (RPKA) Department of Chemical Engineering, Universitas Indonesia, Laboratory of polimer, PUSPITEK and Integrated laboratory of Universitas Islam Negeri Jakarta for the instruments characterization.

\section{References}

1. P.P.D.K. Wulan and D. Angelina. Synthesis of carbon nanotube using camphor with SS 316 as catalytic substrate via oxidative heat treatment preparation method. Proceedings of the $3^{\text {rd }}$ International Symposium on Applied Chemistry 1904020080 (2017)

2. P.P.D.K. Wulan, W.W. Purwanto, and Y.D. Lestari. Identification of Carbon loss in the production of pilot-scale Carbon nanotube using gauze reactor. IOP Conf. Series: Materials Science and Engineering. 334012044 (2017)

3. C.S. Yah, G.S. Simate, K. Moothi, K.S. Maphutha, and S.E. Iyuke. Synthesis of Large Carbon Nanotube from Ferrocene: The Chemical Vapour Deposition Technique. Trends in Applied Sciences Research 6: 1270-1279 (2011).

4. P.P.D.K. Wulan and Y.D. Lestari. The Effect of Oxidative Heat Treatment on the Preparation of Stainless Steel 304 and 316 as the Effective Catalytic Substrate for Carbon Nanotube Growth. IJTech Publication (2017) 
5. K. Dasguota, J.B. Joshi, and S. Banerjee. Fluidized bed synthesis of carbon nanotubes - A review. Chem. Eng. J. 171 841-869 (2011)

6. G.W. Young, S.I. Hariharan, and R. Carnahan. Flow Effects in Vertical CVD Reactor. SIAM J. APPL. Math Vol.52 , No.6 1509-1532 (1992)

7. A. Barreiro, S. Hampel, M.H. Riimmeli, C. Kramberger, A. Grilineis, K. Biedermann, A. Leonhardt, T. Gemming, B. Büchner, and T. Pichler. Thermal Decomposition of Ferrocene as a Method for Production of Single-Walled Carbon Nanotubes without Additional Carbon Sources. J. Phys. Chem B, 110, 20973-20977 (2006)

8. C.M. Seah, S.P. Chai, and A.R. Mohamed. Synthesis of aligned carbon nanotubes. CARBON 49, 46134635 (2011)

9. C. Zhuo, X. Wang, W. Nowak, and Y.A. Levendis. Oxidative Heat Treatment of $316 \mathrm{~L}$ Stainless Steel for Effective Catalytic Growth of Carbon Nanotubes. Appl. Surf. Sci. (2014)

10. P.P.D.K. Wulan and S.B. Wijardono. Finding an Optimum Period of Oxidative Heat Treatment on SS 316 Catalyst for Nanocarbon Production from LDPE Plastic Waste. International Journal on Advance Science Engineering Information Technology, Vol.7 No.2 (2017)

11. J. Kang, J. Li, X. Du, C. Shi, N. Zhao, and P. Nash. Synthesis of carbon nanotubes and carbon onions by CVD using a Ni/Y catalyst supported on copper. Mater. Sci. Eng., A. 475 136-140 (2008)

12. V.O. Nyamori and N.J. Coville. Effect of Ferrocene/Carbon Ratio on the Size and Shape of Carbon Nanotubes and Microspheres. Organometallics 26, 4083-4085 (2007)

13. S. Mopoung. Occurrence of carbon nanotube from banana peel activated carbon mixed with mineral oil. International Journal of the Physical Sciences Vol. 6 (7), pp. 1789-1792 (2011)

14. Q. Zhang, J.Q. Huang, M.Q. Zhao, W.Z Qian, and F. Wei. Carbon Nanotube in Different Shapes. Material Today Vol. 12, no.6 pp. 12-18 (2011)

15. M.A. Hossain and S. Islam. Synthesis of carbon nanoparticles from kerosene and their characterization by SEM/EDX, XRD, and FTIR. American Journal of Nanoscienece and Nanotechnology (2) 52-56 (2013)

16. S. Dardas and M. Faraji. Improve carbon annotube growth inside an anodic aluminum oxide template using microwave radiation. J. Phys. Chem. Solids 116 203-208 (2018) 